\title{
PEDAGOGIA HISTÓRICO-CRÍTICA: ANÁLISE DAS POLÍTICAS CURRICULARES DA REDE PÚBLICA MUNICIPAL DE EDUCAÇÃO DE FOZ DO IGUAÇU - 2007/2017
}

\author{
Jussara Marquezi ${ }^{1}$, Julia Malanchen ${ }^{2}$ \\ ${ }^{1}$ Mestra em Ensino, pelo Programa de Pós-graduação em Ensino pela UNIOESTE, PR. Atua como Coordenadora \\ Pedagógica da Secretaria Municipal de Foz do Iguaçu, PR. E-mail: jummarquezi@gmail.com \\ ${ }^{2}$ Doutora em Educação Escolar pela Universidade Estadual Paulista - Unesp, campus de Araraquara, SP. Pós- \\ doutorado no Institute of Education - University College of London. Atualmente é Professora no Centro de Educação, \\ Letras e Saúde e no Programa de Pós-Graduação em Ensino da Universidade Estadual do Oeste do Paraná - UNIOESTE, \\ Foz do Iguaçu, PR.
}

\section{RESUMO}

A presente pesquisa teve como principal objetivo analisar se a pedagogia histórico-crítica materializa-se nas políticas curriculares, bem como no currículo implantado na rede pública municipal de educação de Foz do Iguaçu no período de 2007 a 2017. Para cumprir com o proposto, diante de uma perspectiva dialética de análise de dados, o percurso do trabalho consistiu em realizar um estudo teórico no qual elencamos os fundamentos da pedagogia histórico-crítica para subsidiar a análise dos documentos direcionadores do trabalho pedagógico na rede municipal anunciada. Os documentos analisados foram: Currículo da Associação dos Municípios do Oeste do Paraná (AMOP), o projeto político-pedagógico de algumas escolas e o Relatório de formação continuada do Núcleo de Tecnologia Municipal (NTM). Objetivamos, por meio da análise do disposto nesse estudo, demonstrar que a pedagogia histórico-crítica se materializa nos fundamentos do currículo implantado, porém, devido a influência das correntes pedagógicas negativas ao ato de ensinar o saber sistematizado, as políticas curriculares, desenvolvidas na rede pública municipal de educação de Foz do Iguaçu nesse período, estão condicionadas às políticas neoliberais, dificultando a efetivação e implementação de uma pedagogia contra hegemônica.

Palavras-chave: Pedagogia Histórico-Crítica. Currículo. Políticas Curriculares. Foz do Iguaçu.

\section{HISTORICAL-CRITICAL PEDAGOGY: ANALYSIS OF THE CURRICULAR POLICIES OF THE MUNICIPAL PUBLIC NETWORK OF EDUCATION OF FOZ DO IGUAÇU - 2007/2017}

\begin{abstract}
The present research had as main objective to analyze if the historical-critical pedagogy materializes in the curricular policies, as well as in the curriculum implanted in the municipal public education of Foz do Iguaçu in the period from 2007 to 2017. To comply with the proposed, before from a dialectical perspective of data analysis, the course of work consisted in carrying out a theoretical study in which we list the foundations of historical-critical pedagogy to support the analysis of the directives of pedagogical work in the announced municipal. The documents analyzed were: Curriculum of the Association of Municipalities of the West of Paraná (AMOP), the political-pedagogical project of some schools and the Continuing Education Report of the Municipal Technology Nucleus (NTM). We aim, through the analysis of the provisions of this study, to demonstrate that historical-critical pedagogy materializes in the foundations of the curriculum implemented, but due to the influence of negative pedagogical currents to the act of teaching systematized knowledge, curricular policies developed in the network public education in Foz do Iguaçu in this period, are conditioned to neoliberal policies, making it difficult to implemen of a pedagogy against hegemonic.
\end{abstract}

Keywords: Historical-Critical Pedagogy. Curriculum. Curricular Policies. Foz do Iguaçu. 


\section{PEDAGOGÍA HISTÓRICO-CRÍTICA: ANÁLISIS DE LAS POLÍTICAS CURRICULARES DE LA RED PÚBLICA MUNICIPAL DE EDUCACIÓN DE FOZ DEL IGUAÇU - 2007/2017}

\section{RESUMEN}

La presente investigación tuvo como principal objetivo analizar si la pedagogía histórico-crítica se materializa en las políticas curriculares, así como en el currículo implantado en la red pública municipal de educación de Foz do Iguaçu en el período de 2007 a 2017. Para cumplir con lo propuesto, ante de una perspectiva dialéctica de análisis de datos, el recorrido del trabajo consistió en realizar un estudio teórico en el cual elencamos los fundamentos de la pedagogía histórico-crítica para subsidiar el análisis de los documentos direccionarios del trabajo pedagógico en la red municipal anunciada. Los documentos analizados fueron: Currículo de la Asociación de los Municipios del Oeste de Paraná (AMOP), el proyecto político-pedagógico de algunas escuelas y el Informe de formación continuada del Núcleo de Tecnología Municipal (NTM). En el análisis de lo dispuesto en este estudio, objetivamos que la pedagogía históricocrítica se materializa en los fundamentos del currículo implantado, pero debido a la influencia de las corrientes pedagógicas negativas al acto de enseñar el saber sistematizado, las políticas curriculares, desarrolladas en la red de la población municipal de educación de Foz do Iguaçu en ese período, están condicionadas a las políticas neoliberales, dificultando la efectividad e implementación de una pedagogía contra hegemónica.

Palabras clave: Pedagogía Histórico-Crítica. Plan de Estudios. Políticas de Currículum. Foz de Iguazu.

\section{INTRODUÇÃO}

O presente trabalho é resultado de parte da pesquisa que teve como um dos objetivos analisar as políticas curriculares implantadas entre os anos de 2007 a 2017 na Rede Pública Municipal de Ensino de Foz do Iguaçu. Para analisarmos os documentos e encaminhamentos dessas políticas no munícipio, retomamos os principais fundamentos da pedagogia históricocrítica e, concomitantemente, analisamos as políticas nacionais que influenciaram as ações locais, no período selecionado.

De acordo com Malanchen (2016), a partir de 1990, as políticas curriculares nacionais expressam a hegemonia de uma ideologia pósmoderna de educação, as pedagogias do "aprender a aprender". Dentro dessa categoria podemos citar o construtivismo e o multiculturalismo, que dentro de suas especificidades negam o trabalho educativo através do ensino do saber sistematizado e defendem segundo Duarte (2016, p. 48), "uma educação pautada na vida, nos processos de construção do conhecimento e na realização de atividades voltadas para questões do cotidiano". Os autores ressaltam que a educação não se resume à prática e ao utilitarismo do cotidiano, e isto significa que não podemos descuidar dos pressupostos teóricos que definem o exercício educativo, ou seja, a concepção de sociedade, educação, homem e ensino aprendizagem, que norteia nossa ação pedagógica.

Desse modo, este trabalho teve por objetivo contribuir para a produção de conhecimento no campo de ensino e pesquisar o currículo, numa concepção materialista histórica e dialética, permitirá compreender a educação nesse movimento histórico, entender que a instrução escolar interfere na sociedade e contribui para a sua transformação. Nesse sentido, enfatizamos que a educação não é neutra e, para que essa mudança aconteça, o conhecimento escolar deve ser organizado com a intencionalidade de produzir nos alunos um posicionamento consciente, diante das escolhas existentes em relação à sociedade em que se vive.

Dessa forma, um currículo escolar, baseado numa perspectiva dialética, prevê a aprendizagem do saber elaborado, pressupõe o desenvolvimento de políticas educacionais que possibilitam a implantação do currículo dentro de uma especificidade emancipadora, fundamentando o trabalho pedagógico numa perspectiva histórica, primando transmitir intencionalmente de forma singular, os diferentes conhecimentos produzidos pela humanidade, buscando o desenvolvimento integral do homem. 
Na região oeste do Paraná, onde a cidade de Foz do Iguaçu está localizada, a partir de 2007, - Currículo Básico Para a Escola Pública Municipal da Região Oeste do Paraná (AMOP, 2007) passou a direcionar as políticas curriculares dos munícipios dessa região. Então, a partir dessa implantação foi proposto o desenvolvimento de ações coletivas e intencionais para a sua efetivação. Para tanto, fez-se necessário um posicionamento dos sujeitos envolvidos no processo, quanto à finalidade do trabalho pedagógico a ser desenvolvido, já que um currículo não se efetiva por si só, sendo necessária a compreensão da totalidade das relações nas quais está inserido.

Em relação a este aspecto, Saviani (2003, p.13) define "o trabalho educativo como o ato de produzir direta e intencionalmente, em cada indivíduo singular, a humanidade que é produzida histórica e coletivamente pelo conjunto dos homens". Destarte, a Pedagogia Histórico-Crítica (PHC) norteada pela concepção materialista histórica e dialética, defende o trabalho como atividade especificamente humana e se coloca na defesa da transmissão pela escola de conteúdos sistematizados, possibilitando que o ser humano tenha acesso ao conhecimento historicamente produzido e acumulado pela humanidade.

Nesse contexto, para a realização da pesquisa, algumas indagações se tornaram pertinentes: quais políticas curriculares foram desenvolvidas nesse período? As ações desenvolvidas refletiam a teoria curricular da pedagogia histórico-crítica ou das pedagogias hegemônicas? Essas reflexões definiram a problemática da pesquisa: qual teoria é apresentada enquanto proposta educacional nas políticas curriculares desenvolvidas na rede municipal de educação de Foz do Iguaçu, após a implantação do currículo da AMOP, no período de 2007 a 2017?

A partir destas questões, o objetivo central do estudo foi definido como: analisar se a pedagogia histórico-crítica se materializa nas políticas curriculares, bem como no currículo implantado na rede pública municipal de educação de Foz do Iguaçu no período de 2007 a 2017. Para responder à questão inicial e atingir o objetivo proposto foi necessário, elencar os fundamentos teórico-metodológicos da pedagogia histórico-crítica e verificar os elementos norteadores do trabalho pedagógico na rede municipal de educação (no período selecionado) no currículo da AMOP, nos Projetos Político-Pedagógico e no Relatório de formação continuada do Núcleo de Tecnologia Municipal. Objetiva-se, por meio da análise do disposto nesses documentos, demonstrar que a pedagogia histórico-crítica se materializa no currículo implantado, porém, devido à influência das correntes pedagógicas opostas à transmissão do saber sistematizado, as políticas curriculares, desenvolvidas na rede pública municipal de educação de Foz do Iguaçu, nesse período, estão condicionadas às políticas neoliberais, dificultando assim sua efetivação.

\section{METODOLOGIA}

Esta pesquisa foi desenvolvida na Rede Pública Municipal de Educação de Foz do Iguaçu. Esta Rede é composta por cinquenta e uma escolas que atendem do primeiro ao quinto ano do Ensino Fundamental. De cunho documental e bibliográfico, o presente estudo buscou fundamento metodológico na perspectiva materialista histórico e dialética de análise de dados. Segundo André (2018),

o método dialético de
Marx permite a
abordagem de
problemáticas que
estabeleçam relações
entre educação, escola,
ensino e sociedade, a
partir do pressuposto de
que a razão e a
compreensão da realidade
concreta são objetivos
possíveis na pesquisa e de
que a verdade não está no
discurso, mas na atividade
teórico prática (práxis), e
suas determinações
(ANDRÉ, 2018, p.4).

Sem dúvida, o método dialético "constitui-se numa espécie de mediação no processo de apreender, revelar, expor a estrutura, o desenvolvimento e transformação dos fenômenos sociais" (FRIGOTO, 2004, p.77). Sendo desenvolvido o conhecimento crítico, a transformação da realidade se dará, não só no plano da informação, como no plano históricosocial, levando a uma reflexão teórica da realidade em busca de transformação social.

Retrata-se a análise documental da seguinte forma: são apontados e discutidos os pressupostos filosóficos, psicológicos e 
pedagógicos do Currículo AMOP (2014). Na sequência, são analisadas, as concepções de homem, de mundo, de conhecimento, de currículo, de educação e de escola, dispostas nos Projetos Políticos Pedagógicos de uma amostra $(10 \%)$ das escolas municipais. Além de debater os dados elaborados a partir de planilhas disponibilizadas pelo NTM sobre a formação continuada ofertada pela Secretaria Municipal de Educação no período proposto para a pesquisa.

Ao utilizar-se da pesquisa bibliográfica, como procedimento metodológico, faz-se primordial o aporte teórico dos autores que defendem a temática da Pedagogia HistóricoCrítica, defensora do saber objetivo produzido historicamente, sendo esses pressupostos primordiais para a análise dos documentos apresentados na pesquisa. A fim de compreender o proposto, foram selecionadas as obras de Veiga (1995), Severino (2008), Saviani (2000), Bueno (2011), Della Fonte (2011), Martins (2011), Maués (2011), Saviani $(2008,2012,2013$, 2014, 2016), Decker (2015), Duarte $(2015,2016)$, Malanchen (2015, 2016), Orso e Malanchen (2016), Antunes (2016) e Orso (2017).

\section{DISCUSSÃO}

A pedagogia histórico-crítica se apresenta como exigência na superação das teorias não críticas e das teorias crítico-reprodutivistas da educação. No Brasil, estas teorias alimentavam a resistência às políticas educacionais do regime militar. No entanto, defendiam a ideia que não haveria saída no campo educacional, pois a escola desempenhava a função de reprodução social. Ao abordar as afirmações feitas por Saviani, Malanchen (2016) ressalta que o autor "discordava, da tese do caráter insuperavelmente alienado da educação escolar" (MALANCHEN, 2016, p. 155). Para Saviani (2012), a educação apresenta um caráter político na luta contra o capitalismo. Sendo assim, era necessário entender a questão educacional baseada no desenvolvimento histórico objetivo, ou seja, nos pressupostos do materialismo histórico e dialético.

A pedagogia histórico-crítica se apresenta no procedimento pedagógico como manifestação teórica do marxismo. Para melhor compreensão dessa pedagogia, especificamos a correlação entre homem, cultura, sociedade, concepção da educação e currículo nessa perspectiva.

A concepção de ser humano, apresentada por Bueno (2011, p.93) dispõe que o homem é "um ser que se faz historicamente, a partir de suas necessidades básicas de sobrevivência que ocorre por meio do trabalho." Assim, pode-se dizer que, na medida em que o ser humano transforma a natureza, consegue extrair dela o que necessita para sobreviver; criar instrumentos para atender suas precisões; socializar-se e desenvolver-se com a consciência e o desenvolvimento de novas atividades que possibilitam a formação de sua cultura.

$\mathrm{O}$ ato de modificar a natureza para suprir suas necessidades básicas é o que se denomina de trabalho. Neste sentido, de acordo com Saviani (2013), o homem deve produzir os elementos de subsistir, bem como, adaptar o natural ao que carece, transformando-o através de suas atividades (individual/coletivas), adequando-o ao que ambiciona para um mundo humano e mais cultural.

Baseando-se nas ideias de Saviani (2008), nas quais ele pontua que, para Marx, a essência humana se encontrava no trabalho, surge uma determinação mais precisa da concepção marxista de homem na qual: "passa a coincidir com a práxis, ou seja, o homem é entendido como ser prático, produtor, transformador" (SAVIANI, 2008, p.227). Neste sentido, a essência humana deixa de ser entendida como abstrata e individual, passando a fazer parte das relações sociais. Em relação a este aspecto, para Bueno (2011), o ser humano se constitui como ser social ao intervir na natureza, modificando-a e oferecendo novas utilidades.

Em linhas gerais, o ser humano "apresenta-se como ser singular dotado de competências intelectual, sensitiva, afetiva e valorativa, capacidades estas situadas nas circunstâncias sócio históricas em que está inserido" (BUENO, 2011, p. 94). Para o autor, o indivíduo é genérico, ou seja, um ser social, que faz parte das relações humanas desenvolvidas no decorrer da história da humanidade. Seguindo o mesmo entendimento, para Malanchen (2016), o início do processo de humanização acontece pela mediação do trabalho, na relação do ser com a natureza, momento no qual começa a produzir cultura, elemento fundamental que os diferencia das demais espécies, sendo por meio da apropriação da cultura que o ser social desenvolve inovações intelectuais. Ainda, segundo a autora, numa perspectiva do materialismo a definição de cultura é ampla:

a) é resultado do trabalho, isto é, da ação do ser 
humano sobre a natureza

e, portanto, define-se como cultura material;

b) juntamente com a cultura material se formam os elementos que compõem a cultura não material ou simbólica, como a linguagem, as ideias, a ciência, a filosofia e a arte;

c) a ciência, a arte e a filosofia são, dessa forma, parte da cultura, e não podem ser confundidas como seu sinônimo;

d) a apropriação da cultura é sempre um processo educativo, ou seja, é necessária a existência de mediações para que a mesma seja transmitida e apropriada no processo de humanização.

(MALANCHEN,

2016, p.108)

Assim, compreende-se que sendo um ser social é através do acesso à cultura que o sujeito se humaniza. Processo que se desenvolve de maneira histórica e deve ser repassado pela instrução das futuras gerações para que tenham instrumentos para atuar em prol das transformações sociais desejadas. Destacando que Della Fonte (2011, p. 36) considera que a luta pela valorização da escola se dá através do "projeto de formação humana omnilateral, entendido como a apropriação ativa do patrimônio cultural pelo indivíduo no processo de auto fazer-se membro do gênero humano", ou seja, os indivíduos ao se apropriarem dos elementos culturais transmitidos por meio da socialização do saber elaborado pela escola, humanizam-se.

Com a mesma compreensão, Saviani afirma que ter o domínio da cultura significa possuir instrumentos indispensáveis para a participação política das massas, assim "o dominado não se liberta se ele não vier a dominar aquilo que os dominantes dominam. Então, dominar o que os dominantes dominam é condição de libertação" (SAVIANI, 2012, p. 55), isto é, quando os sujeitos se apropriam de conteúdos, podem ter as condições para defenderem seus interesses primordiais.
Para tanto, ressalta-se que a pedagogia histórico-crítica tem por objetivo final superação do modelo social capitalista e, portanto, da alienação. A autonomia necessária para o ser humano remover a alienação, produzida nas relações de trabalho, só pode ser desenvolvida por meio do acesso à cultura construída ao longo do tempo pela humanidade. Malanchen (2016) pontua que no processo de ir além da alienação, espera-se que o sistema hegemônico da sociedade capitalista seja superado e outro modelo social seja implantado, no qual o bem comum de toda a humanidade seja o objetivo principal. Desta forma, torna-se necessário entender como $o$ acesso à cultura pode promover a manutenção e/ou a superação do modo de produção vigente. Portanto, a educação é considerada como elemento central na luta para vencer as relações de exploração do homem e da classe social na qual está inserido.

Com essas premissas, o trabalho educativo intencionalmente deve produzir nos indivíduos o conhecimento sobre a cultura historicamente construída. Identificar os elementos culturais que precisam ser compreendidos pelos indivíduos e a forma de transmitir os conhecimentos é o objetivo da educação. Desta maneira, Saviani (2013) ressalta que o homem ao agir sobre a natureza, constrói o mundo histórico da cultura, ou seja, um ambiente mais humano necessário para a superação das diferenças sociais existentes no sistema capitalista. Nessa perspectiva, a educação é vista como um processo de trabalho, no qual, a produção do saber, tanto da natureza, quanto da cultura é considerada produção humana. Podendo ser denominada de 'trabalho não material'.

Neste sentido, para a PHC a especificidade da escola é educativa e articulada à demanda do conhecimento, sendo o saber, o objeto específico do trabalho escolar, assim, "o objeto da educação diz respeito, de um lado, à identificação dos elementos culturais que precisam ser assimilados pelos indivíduos da espécie humana para que eles se tornem humanos de um lado e concomitantemente, à descoberta das formas mais adequadas para atingir esse objetivo" (SAVIANI, 2013, p. 13).

Vale destacar que, para o estudioso, somente com 0 ensino de conteúdos significativos e relevantes será possível concretizar uma prática pedagógica capaz de selecionar a cultura para instrumentalizar a classe 
trabalhadora. Sobre este aspecto, afirma que "o clássico é aquilo que se firmou como fundamental, como essencial" (SAVIANI, 2013, p.17). Isso dispõe o ensino de conteúdos científicos, filosóficos e artísticos em nível mais elaborado. Entretanto, na escola, o clássico é a transmissão/assimilação do saber sistematizado, como parâmetro norteador do que se pretende alcançar.

A relação dos clássicos no
desenvolvimento do gênero humano é importante, pois, segundo Duarte (2016), não se trata só da questão pedagógica, mas também apresenta seu papel na formação do indivíduo, tendo o professor como mediador entre o conteúdo e a configuração pela qual será ensinado. A apropriação do conteúdo clássico é primordial, pois de acordo com os estudos da psicologia histórico-cultural, o processo de ensino deve ser organizado pelo professor levando em consideração os conhecimentos científicos, não cotidianos o que favorece o desenvolvimento das funções psíquicas superiores.

Essa relação é imprescindível e deve ter como referência a concepção de mundo materialista histórica e dialética, a qual a pedagogia histórico-crítica procura defender, sobretudo no que se refere à emancipação da humanidade ao propor o trabalho dos conteúdos clássicos, assumindo uma atitude revolucionária.

Diante dessa perspectiva, Duarte (2016) amparado em Gramsci, dialoga acerca da relação entre a educação escolar e as concepções de mundo considerando que a instrução dos conteúdos clássicos pode, indiretamente, distorcer a formação da compreensão de mundo materialista histórico dialético. Portanto, é necessário reforçar que através de "conhecimentos e posicionamentos acerca da vida, da sociedade, da natureza, das pessoas (incluindo-se a autoimagem) e das relações entre todos esses aspectos" se pode articular que o entendimento de mundo se constitui tanto da individualidade de cada pessoa, como coletivamente, oscilando desde o senso comum até a consciência filosófica (DUARTE, 2016, p. 99).

Considerando o raciocínio do autor, tanto o trabalho como a língua falada e escrita contribui no desenvolvimento da concepção de mundo, fazendo parte da individualidade de cada um. Assim, percebe-se que se torna imprescindível abranger a finalidade do trabalho educativo. Para Duarte (2015, p.50), "o trabalho educativo atinge sua intenção quando cada indivíduo singular se apropria do conhecimento produzido de maneira histórica e coletiva", isto é, o ser humano se acomoda de elementos culturais necessários à sua humanização. Sendo primordial a assimilação de elementos culturais necessários para a mesma, além do posicionamento sobre o processo de formação dos indivíduos.

Em suas conclusões, Duarte (2016, p. 67) descreve que "o conhecimento mais desenvolvido é aquele que permite a objetivação do ser humano de forma universal e livre." Assim, em relação à educação, cabe enumerar os conhecimentos que conduzem ao desenvolvimento pessoal do indivíduo através do trabalho educacional. $O$ autor defende a ideia de que a educação escolar deve desempenhar a função de mediação entre a vida cotidiana e as esferas não habituais de objetivação do gênero humano, especialmente, a ciência, a arte e a filosofia. Considera que a tarefa da escola é a socialização do saber elaborado, a fim de que os indivíduos se apropriem dos elementos culturais necessários a sua humanização, atendendo aos objetivos da pedagogia histórico-crítica de difusão do materialismo histórico e dialético como concepção de mundo ao longo do processo de escolarização da educação infantil até o ensino superior.

A partir do contexto explicitado é possível dizer que a escola tanto pode contribuir com a conservação da sociedade vigente, como em sentido contrário: contribuir para o fortalecimento da classe trabalhadora. Com a intenção de facilitar o entendimento da temática em pauta, para Saviani (2000, p.58) "a escola deve permitir que os dominados tenham acesso aos conhecimentos monopolizados pelos dominantes e os utilizem como arma não só para entender a realidade, mas também para transformá-la", almejando superar o antagonismo por intermédio da seleção e da organização dos conteúdos que possibilitem aos alunos um posicionamento crítico e entendimento coerente e objetivo da realidade.

Destarte, para melhor compreender o desenvolvimento histórico da humanidade, a educação escolar ao se comprometer com a instrução da classe trabalhadora deve se atentar para a transmissão/assimilação do conhecimento objetivo e universal. É importante sugerir que o trabalho educativo é uma produção intencional e deve ter como resultado a humanização do sujeito socialmente inserido em um contexto. 
Mais do que isto, Saviani (2012) propõe um método de ensino no qual educação e sociedade estejam vinculados. Dessa maneira, para o autor, caso fosse possível traduzir esse método de ensino em forma de passos, esse procedimento poderia ser dividido em cinco momentos:

1ㅇ) o ponto de partida seria a prática social inicial, que é comum a professor e alunos; entretanto, os sujeitos podem se colocar em papéis sociais diferenciados, já que, professor e alunos diferem de níveis de compreensão da prática social;

20) seria a problematização, a identificação dos principais problemas postos pela prática social e a assimilação dos conhecimentos necessários para resolvê-los;

3ㅇ) a instrumentalização, ou seja, a apropriação dos instrumentos teóricos e práticos através da transmissão direta e/ou indireta do professor, das ferramentas culturais necessárias à luta social, para a resolução dos problemas detectados na prática social;

4) a catarse, é o momento da incorporação dos instrumentos culturais, modificados para elementos ativos de transformação social;

5) o momento ou o ponto de chegada seria a prática social final, neste estágio os alunos ascendem ao nível de conhecimento em que se encontrava o professor no ponto de partida.

Para melhor descrever, Saviani (2012, p. 72) recorda que o "momento catártico pode ser considerado o ponto culminante do processo educativo, pois é ai que se realiza, pela mediação da análise levada a cabo no processo de ensino, a passagem da síncrese à síntese". Reforçando que a passagem do conhecimento empírico para o conhecimento concreto é mediado pela análise. Ainda de acordo com Saviani (2014, p. 44), "a sociedade está dividida em classes cujos interesses são antagônicos, a educação serve a interesses de uma ou de outra das classes sociais fundamentais". De tal modo, o ensino não se dissocia da sociedade da qual faz parte, sendo necessário entender a função política da escola e seu papel de manutenção ou transformação da sociedade.

Neste ponto, Duarte (2016) lembra que, no campo da política educacional brasileira, muitas vezes, a formação de um sistema educacional não garante a apropriação do saber sistematizado. Por isso, torna-se imprescindível compreender a finalidade do fazer educacional, pois, no decorrer do processo, o ser humano deve se apropriar de elementos culturais necessários a sua humanização. Sendo assim, primordial a apropriação de elementos culturais necessários para a formação íntegra, além do posicionamento no desenvolvimento dos indivíduos social.

Ao abordar sobre os conteúdos escolares e o currículo, Malanchen (2016, p. 166) ressalta a importância de compreender que "o saber escolar, ou seja, o currículo é o saber objetivo, organizado e sequenciado de forma a possibilitar seu ensino e sua aprendizagem ao longo do processo educativo". Sendo assim, um currículo escolar, baseado numa perspectiva marxista, deve estar assentado na objetividade científica e histórica, em busca da emancipação humana e social da classe trabalhadora. Assim sendo, temse por objetivo compreender a pedagogia histórico-crítica enquanto defensora da socialização do saber objetivo, convertido em saber escolar, ao longo de todo processo educativo, como base para a formação da concepção de mundo marxista.

Objetivando adentrar, especificamente, no assunto sobre o método materialista histórico dialético, faz-se necessário entender que o currículo na perspectiva revolucionária, segundo Orso (2017, p.163), implica na transmissão pela escola dos conhecimentos significativos historicamente produzidos e pressupõe que "por meio da prática pedagógica, do conhecimento, ou então, dos conteúdos escolares os alunos aprendam a ler o mundo". Desta forma, a apropriação das informações significativas deve possibilitar aos alunos a compreensão de seu papel, enquanto trabalhador, por meio da consciência de classe e se perceber como instrumento de transformação social.

Então, ao definir os elementos culturais que necessitam ser apreendidos é preciso ter clara a noção do que é fundamental e essencial, ou seja, "clássico". A seleção dos conteúdos para o trabalho pedagógico deve organizar os meios para que os sujeitos, dentro de sua individualidade, adquiram o que a humanidade produziu historicamente ao longo dos tempos. Neste sentido, Saviani (2013) reforça o papel da escola na socialização do saber sistematizado, elaborado, erudito e não do saber espontâneo, fragmentado e do cotidiano.

Saviani $(2013$, p. 15) quando se refere ao currículo afirma que é um "o conjunto das atividades nucleares desenvolvidas pela escola". 
O que pressupõe diferenciar as atividades curriculares das extracurriculares, com 0 propósito de distinguir o que é principal do que é secundário tendo em vista o significado político da ação educativa. $O$ autor enfatiza que "o saber escolar pressupõe a existência do saber objetivo (e universal)". Aliás, o que se convencionou chamar de saber escolar não é outra coisa senão a organização sequencial e gradativa do saber objetivo disponível numa etapa histórica determinada para efeito de sua transmissão/assimilação ao longo do processo escolarização. (SAVIANI, 2013, p. 54)

É de suma importância relembrar que um dos pilares da pedagogia histórico-crítica, a psicologia histórico-cultural, vem, através dos estudos da escola de Vigotski, assegurar a relevância dos conteúdos clássicos para o desenvolvimento das funções psicológicas superiores. Malanchen (2016) afirma que, para Vigotski, as funções superiores essencialmente humanas eram consequência da relação do homem com a cultura e com o trabalho, modificando, neste processo de desenvolvimento histórico, suas funções psicológicas.

Dessa forma, pode-se dizer que o fazer educativo deve desenvolver as questões subjetivas, tendo o trabalho como princípio educativo. Assim sendo, Martins (2011, p. 57) assegura que cabe à educação escolar "instrumentalizar os indivíduos para a atividade consciente, para a transformação das circunstâncias e de si mesmos", é possível prever que o homem é capaz de captar a realidade em sua historicidade por meio do pensamento teórico. Todavia, ao realizar o trabalho social o indivíduo, além de se adaptar à realidade, deve construí-la para superar o conhecimento empírico almejando a transformação desejada. Esta modificação estabelecida através do pensamento teórico é que conduz à direção do conhecimento conceitual.

Neste sentido, pode-se observar que, para o indivíduo passar de uma elaboração de conceitos espontâneos para os científicos é necessário que a organização do currículo esteja pautada no saber objetivo, ou seja, nos conteúdos clássicos, sistematizados e indispensáveis à formação do pensamento por conceitos. Contudo, há que se considerar que:

[...] na perspectiva histórico/crítica, o específico da educação escolar é lidar com o

\begin{abstract}
conhecimento
sistematizado (metódico): sua transmissãoassimilação/apropriação, que exige - ao mesmo tempo permite - o desenvolvimento do raciocínio (metódico sistemático), próprio do pensamento teórico, do conhecimento científico, que não é somente representação, descrição, mas que também não se restringe a imaginação, especulação (SAVIANI, 2000, p.47).
\end{abstract}

Ao viabilizar o acesso ao conhecimento sistematizado, a escola deve incentivar o aluno a ter interesse pelo saber científico, o que não significa anular a informação adquirida no senso comum. Mas, somente, pela mediação da escola, num movimento dialético, é possível acontecer o ingresso do saber espontâneo ao cientificamente elaborado buscando promover uma prática que, verdadeiramente, se articule aos interesses do ser humano.

Considerando que o saber escolar é a organização sequencial e gradativa do saber objetivo, Saviani (2013) reserva para o termo currículo as atividades essenciais que a escola não pode deixar de desenvolver sob pena de descaracterizar, de perder a sua especificidade. A determinação dos métodos e dos processos de ensino/aprendizagem é o fim que se deseja atingir no processo educacional. Portanto, o ensino escolar, desde que organizado adequadamente, será apropriado para que o infante aperfeiçoe e desenvolva capacidades, fundamentalmente humanas.

Em relação ao saber escolar, Malanchen (2016, p. 177) ressalta que "o currículo envolve os conhecimentos científicos, artísticos e filosóficos que possibilitem a compreensão da realidade natural e social para além das aparências". Nesta perspectiva, a educação escolar é uma aliada no projeto de formação do indivíduo que alcança a máxima capacidade para pensar e compreender a realidade, além do que as aparências indicam. Segundo a mesma autora, para se cogitar o currículo à luz da pedagogia histórico-critica é imprescindível expor a amostra de organização pretendida que esteja conexa com a conjetura teórica da pedagogia. Utilizando- 
se da metodologia dialética como referência para a organização curricular, a oscilação será do empírico ao abstrato e deste ao concreto, possibilitando a assimilação do que é essencial.

As reflexões feitas por Duarte (2016, p. 95) sobre a temática em pauta retratam que "ensinar conteúdos escolares como ciência, história, geografia, artes, educação física, língua portuguesa e matemática é ensinar as concepções de mundo veiculadas por esses conhecimentos, ou seja, é educar". Desta maneira, torna-se indispensável compreender as relações entre as concepções de mundo, de prática social e de ciência, sempre numa visão histórico/dialética. Como pode ser observada, a educação escolar em sua especificidade, pretende a transmissão dos conhecimentos científicos, artísticos e filosóficos com a intenção de que os sujeitos se apropriem do conhecimento humano produzido ao longo da história. Essa socialização deve ser de maneira contextualizada com uma proposta de articulação entre as disciplinas, ou seja, que haja diálogo entre as mesmas.

Neste aspecto, um ponto a ser considerado é a junção dos conhecimentos para a realização do trabalho desenvolvido pelo ser humano, elemento defendido por Malanchen (2016) quando se refere à concepção materialista que se faz necessária para a superação das visões unilaterais. Assim sendo, a ideia é de que o caminho para a organização de um currículo (como eixo norteador) considere o que é próprio do ser humano: o trabalho como característica humana de transformação da natureza. Sobre essa questão, Orso e Malanchen (2016) dispõem que:

[...] a organização do currículo deve propiciar não somente meios para que sejam compreendidos os conhecimentos nele inseridos, como, também, o movimento de contradição que existe na sociedade e o modo como a classe trabalhadora nele se insere. O currículo da escola é, deste modo, uma seleção intencional de uma porção da cultura universal produzida historicamente. (ORSO; MALANCHEN, 2016, p.3)
Sendo assim, Saviani (2000, p. 46) reforça que "o conhecimento não é mero reflexo da realidade objetiva, nem simples momento da atividade livre e criadora do homem". O conhecimento parte da realidade, sendo histórico e socialmente determinado, desta forma, não é neutro. Para o autor, a socialização do saber elaborado permeia democratizar e transformar a sociedade, possibilitando aos dominados, a superação de sua condição ao apropriar-se do saber sistematizado. Dessa maneira, pressupõe o ensino dos conteúdos escolares elaborados de maneira que sirvam como ferramenta reflexiva para os sujeitos sociais intervirem na realidade que desejam transformar.

Objetivando adentrar essas reflexões, Duarte (2016, p. 116) ressalta que, sobre o ensino de ciência, de arte e de filosofia é interessante destacar que fazem parte das esferas elevadas de objetivação do gênero humano. Assim, discutir sobre os conhecimentos que devem fazer parte dos currículos é tarefa dos educadores, sendo esta uma tomada de posição, os mesmos devem conscientizar-se de que o ensino das ciências é um ato educativo que permite a objetivação do homem na sua humanização. A questão descrita pelo autor não pode ser uma incógnita para os catedráticos que ao realizarem "o trabalho de construção dos currículos escolares, de produção e de seleção dos livros sejam empregados como material didático".

Saviani (2013, p. 15) defende a escola como um ambiente adequado para proporcionar às novas gerações a aquisição ao saber elaborado, científico, sendo o currículo escolar a sistematização desta sabedoria. Para o autor, "o currículo é o conjunto das atividades nucleares desenvolvidas pela escola", ou seja, atividades que o educandário necessita desenvolver como meio de oportunizar aos educandos diferentes elementos de aprendizagem. Talvez por essa razão, a pedagogia histórico-crítica se opõe à separação entre conhecimento e concepção de mundo.

É preciso destacar que alguns estudiosos, assim como Duarte (2016), apoiam o trabalho com os conteúdos clássicos, não se limitando ao pragmatismo e nem ao imediatismo, diferenciando das pedagogias hegemônicas que procuram cogitar somente conhecimentos da cotidianidade. Um exemplo a ser citado é o construtivismo e as pedagogias do aprender a aprender que não se referem a uma concepção de mundo, não demonstram suas posições 
ideológicas, assumindo uma pseudo neutralidade, dando ênfase, especificamente, apenas aos métodos e procedimentos.

Seguindo o mesmo pensamento, Saviani (2012) dispõe que, uma pedagogia voltada aos interesses populares necessita de métodos de ensino eficientes que valorizem a cultura historicamente acumulada, que respeite 0 interesse, os ritmos de aprendizagem, além do desenvolvimento psicológico dos alunos. Contudo, não deve esquecer-se da importância da sistematização lógica dos conhecimentos, atendendo ao processo de transmissão/assimilação dos conteúdos cognitivos. Conforme o autor:

[...] já a filosofia da práxis, tal como Gramsci chamava o marxismo, é justamente

a teoria que está empenhada em articular a teoria e a prática unificando-a na práxis. É um movimento prioritariamente prático, mas que se fundamenta teoricamente

alimentando-se da teoria para esclarecer o sentido, para dar direção à prática. Então, a prática tem primado sobre a teoria, na medida em que é originante. A teoria é derivada (SAVIANI, 2013, p, 120).

Partindo deste princípio, pode-se dizer que a prática é a finalidade da teoria e, para se desenvolver, necessita ser embasada tendo clareza da importância do método para o desenvolvimento da práxis. Desta forma, a pedagogia histórico-crítica participante de uma teoria marxista, apresenta-se como base para a organização do currículo escolar. A intencionalidade e a direção na organização da ação docente são importantes para garantir as formas mais adequadas para que os conteúdos clássicos, essenciais, sejam incorporados pelos discentes.

Em linhas gerais, pode-se concordar com Saviani (2013, p. 122) ao definir que "a lógica dialética é uma lógica concreta. É a lógica dos conteúdos". Neste aspecto, se considera o currículo escolar, atualmente dividido em disciplinas, resultado de uma estrutura social centrada na divisão de trabalho, porém se objetiva a superação da divisão das disciplinas para chegar-se a um conhecimento mais amplo, produzido, coletivamente, articulado a uma visão de totalidade.

Baseando-se nas ideias de Malanchen (2016, p. 166) é possível considerar que a sequência dos conteúdos é fundamental quando consideram "as características do psiquismo dos sujeitos envolvidos na atividade educativa". Para a autora, deve ocorrer a seleção intencional e o encadeamento dos conhecimentos que devem ser socializados para toda a população, para que estes consigam garantir o entendimento da realidade natural e social para além das aparências, como requisitos fundamentais para o processo de humanização de cada indivíduo. Então, a organização curricular à luz da pedagogia histórico-crítica deve tomar como referência o método dialético, "num movimento do empírico ao abstrato e deste ao concreto, ou seja, da síncrese à análise e desta à síntese" (MALANCHEN, 2016, p. 198). Este movimento se denomina como método de ensino que deve transpor o conceito da coerência dialética concreta para a organização curricular.

Neste sentido, para melhor compreensão da disciplinaridade, na concepção de Malanchen (2016, p. 201), se faz necessário entender que "é o momento de decomposição consecutiva do conhecimento, para que ele seja apreendido em suas categorias mais simples, porém, mais aprofundado", uma vez que o objetivo da pedagogia histórico-crítica é a apreensão da totalidade do conhecimento na organização dos conteúdos, permitindo o movimento constante do todo às partes e delas ao todo. Este aparelhamento da informação em disciplinas e o momento analítico são necessários para chegarse à totalidade concreta através da articulação das disciplinas. Deste modo, para que a escola não neutralize o seu papel no desenvolvimento humano é preciso organizar metodologias e descobrir formas adequadas para atingir a finalidade a que se propõe.

Neste contexto, a seleção do conhecimento deve ser intencional e planejada para transmitir os conhecimentos como instrumento de superação para o desenvolvimento da classe trabalhadora, sabendo que a produção do saber é social e acontece nas relações sociais. Neste sentido, Saviani (2013, p. 67), descreve que "a elaboração do saber implica expressar de forma elaborada o saber que surge da prática social". Para tanto, é 
preciso que a escola, como a responsável pelo acesso aos instrumentos de elaboração e sistematização da ciência às novas gerações, contribua para a prática social de luta em busca do desenvolvimento da consciência de classe, que emerge a partir do domínio do saber elaborado pela classe trabalhadora. Advertindo que a construção do saber acontece na escola onde é o espaço apropriado para a aquisição do saber erudito, sistematizado, a fim de humanizarse e ser capaz de superar as relações de exploração existentes. Portanto, ao definir que conteúdo pretende ofertar aos alunos, a escola induz, de forma indireta, a maneira como os sujeitos poderão intervir na sociedade. Assim, segundo Orso e Malanchen (2016, p.3) "por isso, as tensões e debates sobre currículo têm um forte caráter político".

Ao fortalecer o papel da escola, Saviani (2016) enaltece a socialização do saber sistematizado elaborado e ressalta que o currículo deve ser estruturado para garantir a obtenção dos instrumentos de acesso a esse saber. $O$ autor entende que ao cumprir sua finalidade, a instituição escolar, conseguindo definir os elementos culturais que carecem ser apreendidos, necessita-se ter claro o que é fundamental e clássico, para depois selecionar os conteúdos a serem disseminados pelo trabalho pedagógico.

\section{RESULTADOS}

Na sequência retratam-se, os resultados da análise dos dados coletados no currículo AMOP (2014), nos Projetos Políticos Pedagógicos de uma amostra (10\%) das escolas municipais e das planilhas disponibilizadas pelo NTM sobre a formação continuada ofertada pela secretaria pública municipal de educação, ou seja, as políticas curriculares implantadas na rede pública municipal de educação de Foz do Iguaçu no período de 2007 a 2017. Para esse trabalho utilizou-se como fonte de pesquisa a 3a edição da proposta curricular lançada em 2015, especificamente a segunda seção, que apresenta os pressupostos filosóficos, psicológicos, pedagógicos e legais para o Ensino Fundamental - séries iniciais. Vislumbramos que, construído coletivamente, esse documento expressa 0 modelo de educação, de sociedade e de homem que se deseja formar. Destarte, os pressupostos filosóficos dispõem sobre a concepção de homem, de sociedade e a compreensão de educação, considerando também que são essas concepções que definem a direção dos demais fundamentos. Os psicológicos apresentam a concepção de desenvolvimento e aprendizagem e os pedagógicos definem um modo de pensar e fazer da educação, a fim de garantir que os pressupostos filosóficos se efetivem, o documento apresenta também os pressupostos legais que se referem às bases da legislação educacional que sustentam a proposta curricular.

De acordo com a AMOP (2014, p. 14), o currículo parte de preceitos baseados nos materialismo histórico e dialético e apresenta três pressupostos "o primeiro é que a realidade não é estática, pois se encontra em constante movimento; o segundo é que são os homens que fazem a história diante de determinadas necessidades e condições sociais; o terceiro é que a base da sociedade está fundada no trabalho social". Partindo do princípio dialético, essas pressuposições, embora diferentes, não se separam e definem a vida do homem. Dessa forma, a realidade e o indivíduo se formam no processo no qual o homem, ao trabalhar a natureza para satisfazer as suas necessidades, transforma o meio e a si mesmo.

O trabalho "é o cerne, o âmago da teoria marxiana na formação dos seres humanos" (ANTUNES, 2016, p. 60). Segundo o autor, é por meio do trabalho que o ser humano se humaniza. O processo histórico de humanização está inserido no processo de relações de produção dos bens materiais e intelectuais que não produzimos sozinhos. Saviani (2013) explicita que, "trata-se aqui da produção de ideias, conceitos, valores, símbolos, hábitos, atitudes, habilidades. Numa palavra, trata-se da produção do saber, seja do saber sobre a natureza, seja do saber sobre a cultura", ou seja, é "o conjunto da produção humana" (SAVIANI, 2013, p. 12). Dessa maneira afirma que a educação se situa na modalidade de trabalho não material.

De acordo com a proposta curricular, ao adotar esses princípios teóricos, busca-se "desmitificar as relações sócio-históricas, as ideologias e as representações de mundo presentes na realidade e no currículo escolar, de modo a relacionar ciência, técnica e política" (AMOP, 2014, p.15). Cabe à escola, portanto, o papel de contribuir para esclarecer as contradições sociais, a fim de superar a alienação e, quem sabe, a divisão de classes. Ao dar sequência à análise do currículo (2014), explicitase como se apresentam os fundamentos da 
concepção sociocultural, que define os pressupostos psicológicos do currículo.

Baseada nos estudos de Vigotski, essa concepção se destaca, pois, tem como "pressuposto fundamental que a interação do sujeito com o objeto e deste com o sujeito $(S \leftrightarrow O)$ ocorre no contexto social, depende de relações de mediação" (AMOP, 2014, p. 17). Para Malanchen (2016), a psicologia histórico-cultural fundamenta a pedagogia histórico-crítica, e assim, "assegura que a correta organização do processo de ensino pelo professor por meio de conhecimentos científicos, ocorrido no espaço escolar, favorece o desenvolvimento psíquico". A concepção apresentada no documento curricular coloca a importância de entender "quem é o sujeito que aprende, como ele aprende, quais são as relações existentes entre o ato de aprender e - desenvolvimento das funções psíquicas" (AMOP, 2014, p.21), ressaltando a importância de conteúdos relevantes e significativos dentro do currículo para que a aprendizagem de fato ocorra.

Em linhas gerais, o documento curricular analisado, em sua concepção, parte do entendimento de que o homem se apropria e explora a natureza para suprir suas necessidades transformando-a, diferenciando-se dos outros animais de acordo com suas necessidades e estabelece relações com os outros seres humanos e com o meio.

Numa perspectiva histórica, desde os primórdios da ocupação e colonização do Oeste paranaense a escolarização teve seu papel nas condições de reprodução social dos grupos sociais aqui estabelecidos. Emer (1991, p. 5) aponta que a escola é responsável por vínculos fundamentais com a experiência de vida, com a visão de mundo, com a cultura. "Ela se desenvolve no interior do processo social concreto, na sua totalidade e complexidade e constitui parte da história dos homens". Nesse processo histórico relacionam-se os movimentos migratórios de diferentes origens, novas formas de produzir subsistência e as mudanças econômicas e sociais pelas quais passou a região, o que contribuiu para a construção um modelo escolar de acordo com as relações sociais que se estabeleciam no decorrer desse processo.

Ao estabelecer essas relações para solucionar intencionalmente suas necessidades, 0 homem desenvolve funções psíquicas, essa relação se dá através do acesso ao domínio da linguagem e da cultura. Nesse contexto, de acordo com a abordagem histórico-cultural apresentada no currículo "o trabalho e a linguagem são instrumentos mediadores indispensáveis à sobrevivência humana e são, também, os elementos propulsores que, construídos histórica e socialmente, influenciam as relações sociais e a forma de compreender o mundo" (AMOP, 2014, p. 19).

Sendo assim, o homem, enquanto ser social constrói sua identidade coletiva e sua individualidade através de suas relações. Nessa concepção, a linguagem assume uma posição de destaque, pois nos transforma no processo de apropriação de mundo, afinal não é apenas adquirida por nós, mas também, no curso do desenvolvimento, nos constitui, nos transforma e é mediadora de todo esse processo de apropriação de mundo e de nós mesmos ao longo da vida. Dentro dessa perspectiva, a educação assume um importante papel no que diz respeito à superação das relações sociais de exploração, pois o desenvolvimento do homem possibilita desenvolver a natureza humana em suas múltiplas possibilidades.

Quanto aos pressupostos pedagógicos do currículo AMOP (2014), o documento destaca a importância de definir o método e a metodologia que o sustentam, procurando não priorizar os encaminhamentos metodológicos, lembrando que teoria e prática não se separam. A partir disso, define que, "a educação é trabalho, é uma atividade mediadora no seio da prática social" (AMOP, 2014, p.22). Em linhas gerais, dispõe que a educação deve contribuir para efetivar o processo de humanização do homem, em seu caráter dialético, pois humanizar-se é transformar-se e transformar a realidade. O princípio educativo da escola deve ser o trabalho em busca de uma formação omnilateral do sujeito, uma formação voltada ao desenvolvimento de todas as dimensões humanas.

Os pressupostos curriculares apresentados no documento defendem que a educação compromissada com a transformação deve relacionar teoria e prática por meio de conteúdos científicos. Cabe lembrar que essa teoria não é neutra e nem deve ser separada da prática. Nas palavras de Saviani, "a neutralidade é impossível porque não existe conhecimento desinteressado" (SAVIANI, 2013, p.8). A educação ao realizar seu papel de socialização do conhecimento está cumprindo sua função política, independentemente de ter ou não 
consciência disso. O conhecimento em sua totalidade deve ser historicamente acumulado, partindo dos conceitos espontâneos para os conceitos científicos.

Afirma-se no documento curricular que a efetivação de um currículo comprometido com a transformação deve apresentar uma metodologia adequada em relação ao conteúdo escolar. Ou seja,

[...] a forma como se concebe os conteúdos é determinante para o desenvolvimento omnilateral dos sujeitos. Nesse sentido, é importante abordar sobre a concepção de conhecimento que orienta esse Currículo. De antemão, afirmamos que os conteúdos curriculares, objeto do processo de ensino e de aprendizagem, caracterizam-se por sua natureza científica (AMOP, 2014, p. 22).

O currículo AMOP (2014) se estrutura por disciplinas como forma de esclarecer cada uma delas, porém ressalta que não se deve pensá-las de forma isolada. Nessa perspectiva, entende-se que o conteúdo escolar não deve ser trabalhado de forma fragmentada, em etapas e linearmente. De acordo com Malanchen (2016),

$$
\begin{aligned}
& \text { [...] um currículo pensado } \\
& \text { com base na pedagogia } \\
& \text { histórico-crítica, dentro } \\
& \text { das limitações existentes, } \\
& \text { pode ser disciplinar, } \\
& \text { porém com a concepção } \\
& \text { de mundo do } \\
& \text { materialismo histórico e } \\
& \text { dialético, devendo propor } \\
& \text { a articulação das } \\
& \text { disciplinas considerando o } \\
& \text { elemento fundante do ser } \\
& \text { humano e de todo } \\
& \text { conhecimento produzido } \\
& \text { que é o trabalho } \\
& \text { (MALANCHEN, 2016, p. } \\
& \text { 210). }
\end{aligned}
$$

Deve ser um movimento constante em um processo de construção histórico-social. Duarte (2016) dispõe a partir dos estudos de Saviani, que a pedagogia histórico-crítica "postula que a especificidade da educação escolar no interior da totalidade da prática social é a socialização dos conhecimentos científicos, artísticos e filosóficos por meio dos clássicos" (DUARTE, 2016, p. 96). Defende também que ao socializar o conhecimento em sua forma mais elaborada, pode-se alcançar a difusão do materialismo histórico e dialético como concepção de mundo.

Com a intenção de propiciar o desenvolvimento do educando, o documento analisado defende a necessidade de organizar o processo educativo levando em consideração o conhecimento científico. Saviani (2012) defende que uma pedagogia articulada "com os interesses populares valorizará, pois, a escola, não será indiferente ao que ocorre em seu interior, estará empenhada em que a escola funcione bem, portanto estará interessada em métodos de ensino eficazes" (SAVIANI, 2012, P.69). O método defendido pelo estudioso mantém o vínculo entre a educação e a sociedade, partindo da prática social comum a professores e alunos. Sendo assim, o currículo, define que:

Nessas relações,
objetivando a apropriação
do saber produzido pela
humanidade, o educador
parte do simples
(concreto) para a síntese
(concreto pensado). As
abstrações são mediações
que permitem tornar o
concreto, um concreto
pensado. Por isso, faz-se
necessário partir dos
conceitos espontâneos
para se construir os
conceitos científicos. Para
partir do simples, a
realidade sensível, deve
ser o ponto de partida e
de chegada, mas o ponto
de chegada deverá conter
elementos do universal,
agregados ao particular.
Entretanto, o ponto de
partida e o de chegada
não são os mesmos, pois o
ponto de chegada, ao se
revelar como síntese de
muitas determinações,
constitui-se em um novo
ponto de partida (AMOP,
2014, p.24).

Considera-se, no documento curricular, que a relação entre o contexto escolar e o 
contexto social deve ser uma relação dialética de transmissão do conhecimento sistematizado produzido pela humanidade, em busca da humanização do homem, não um homem alienado, mas um sujeito reflexivo capaz de transformar sua prática social. Assim concorda com Saviani (2012), quando dispõe que a pedagogia histórico-crítica se empenha em "colocar a educação a serviço da referida transformação das relações de produção", ou seja, posiciona-se em defesa dos interesses da classe trabalhadora (SAVIANI, 2012, p. 76).

Sintetizando, verificamos que o currículo AMOP (2014) apresenta uma perspectiva teórica que se contrapõe às teorias neoliberais presentes na política educacional brasileira, pois seus pressupostos filosóficos, psicológicos e pedagógicos têm a influência da pedagogia histórico-crítica, fundamentada no materialismo histórico e dialético. Uma teoria marxista do currículo procura a superação da alienação e defende a objetividade do conhecimento como instrumento de superação. Nesta concepção, a classe trabalhadora deve ter condições de lutar pela mudança da sociedade. Malanchen (2016) dispõe que a produção cultural do homem se dá em sua ação sobre a natureza, construindo nesta relação sua humanidade.

Enquanto que em nossa realidade local vigorava um currículo materialista em busca do desenvolvimento integral do sujeito, no cenário da educação nacional, a implantação da Lei de Diretrizes e Bases da Educação Nacional (LDBEN 9394/96) deu origem a um debate sobre o currículo escolar que, após sua implantação, gerou diversas reformas nas políticas curriculares em toda a educação básica brasileira, numa época de globalização e pós-modernidade. 0 currículo assumiu uma perspectiva multicultural e as "pedagogias do aprender a aprender" adquiriram a concepção idealista de educação, com ênfase na diversidade, desviando a visão das questões relativas às classes sociais para as questões de gênero, raça, etnia e outras individualidades dos grupos culturais, valorizando a cultura de cada um.

Assim, sabendo que o currículo indica a direção da sociedade que se quer produzir, e que é a partir do conhecimento sistematizado que o currículo deve ser elaborado para garantir a efetivação desse documento com o intuito de alicerçar a educação para as séries iniciais do Ensino Fundamental, a proposta curricular deve estar refletida na construção de um "Projeto
Político-Pedagógico

explicitamente comprometido com a humanização do homem, o que exige o engajamento de cada um" (AMOP, 2014 , p. 23). A fim de confirmar, ou não, o que foi apresentado no currículo, buscou-se apresentar, qual teoria pedagógica se apresenta nos Projetos Político-Pedagógicos das escolas públicas municipais de Foz do Iguaçu e na política de formação continuada ofertado pelo NTM.

Primeiramente, destaca-se que o artigo 12, inciso I da LDBEN 9.394/96, atribui aos estabelecimentos de ensino, elaborar e executar sua proposta pedagógica. Essa autonomia estabelecida em nossa legislação permite à escola delinear sua própria identidade enquanto instância social, servindo de base para a construção de um projeto coletivo, intencional. Dessa maneira, "projeto é tomado aqui no sentido de um conjunto articulado de propostas e programas de ação, delimitados, planejados, executados e avaliados em função de uma finalidade, que se pretende alcançar e que é previamente delineada mediante a representação simbólica dos valores a serem efetivados" (SEVERINO, 2008, p. 1). Ao construir os projetos políticos-pedagógicos, planeja-se o que tem intenção de fazer, de realizar. Essa intencionalidade, que articula todas as ações, vai nortear a proposta pedagógica das escolas, ou seja, seu trabalho educativo.

Para isso, a construção do projeto político-pedagógico necessita de um referencial teórico que fundamente sua prática pedagógica. Nesse sentido, Veiga (1995) afirma:

Temos que nos alicerçar nos pressupostos de uma teoria pedagógica crítica viável, que parta da prática social e esteja compromissada em solucionar os problemas da educação e do ensino de nossa escola. Uma teoria que subsidie o projeto políticopedagógico e, por sua vez, a prática pedagógica que ali se processa deve estar ligada aos interesses da maioria da população. Fazse necessário, também, o domínio das bases teóricometodológicas indispensáveis à concretização das concepções assumidas 
coletivamente (VEIGA, 1995, p. 3).

Ressalta-se que, muitas vezes, para organizar o trabalho pedagógico da escola é preciso refletir sobre a organização da sociedade, dessa forma, o projeto político-pedagógico "exige dos educadores, funcionários, alunos e pais a definição clara do tipo de escola que intentam, requer a definição de fins. Assim, todos deverão definir o tipo de sociedade e o tipo de cidadão que pretendem formar" (VEIGA, 1995, p. 4).

A partir disso, no intuito de verificar se os pressupostos da pedagogia histórico-crítica como elementos norteadores do trabalho pedagógico se apresentam nos projetos político-pedagógicos das escolas da rede municipal de educação, a pesquisa tem como elementos de análise: a concepção de homem, de mundo, de conhecimento, de currículo, de educação e de escola propostas nesses documentos.

A elaboração da Proposta PolíticaPedagógica das escolas públicas municipais sempre seguiu as orientações do Núcleo Estadual de Educação de Foz do Iguaçu. Segundo a instrução normativa no 003/2015 - SUED/SEED, inciso 6.3:

A instituição de ensino deverá elaborar um único Projeto Político-

Pedagógico/Proposta

Pedagógica,

contemplando todas as suas ofertas de ensino, de forma que as ações e intenções previstas e explicitadas no documento se torne um projeto de escola em sua totalidade, evitando a fragmentação e a incoerência (SUED/SEED № 003/2015).

A Equipe da SMED disponibiliza um roteiro para orientação das escolas quanto à construção do Projeto Político-Pedagógico. Em 2017, esse roteiro definiu a organização do documento, nesse período, sendo que o marco conceitual deveria ser construído observando os seguintes conceitos:

Concepção de educação, infância, criança, desenvolvimento humano, conhecimento, currículo, seleção e organização dos conteúdos, conhecimentos e atividades no trabalho pedagógico, concepção de ensino e aprendizagem, concepção de alfabetização e letramento, gestão escolar, avaliação do desenvolvimento integral aluno, e de recuperação paralela, concepção e articulação entre as ações, cuidar, brincar, educar e desenvolvimento humano, conforme estabelecido no Currículo da AMOP, 2014 (ROTEIRO, SMED, 2017).

De acordo com os dados apresentados nos Projetos Político-Pedagógicos das escolas municipais, são necessárias algumas reflexões sobre a coerência na organização desse documento junto às instituições escolares. 0 Projeto Político-Pedagógico, como já definimos anteriormente, deve expressar o movimento da prática pedagógica de acordo com as concepções assumidas no marco conceitual para a organização do trabalho pedagógico escolar.

Pode-se afirmar, diante das concepções apresentadas nos PPPs de 2007/ 2010 e 2013, que as escolas demonstram certa autonomia, a qual - junto à liberdade - faz parte da ação pedagógica. De acordo com Veiga (1995), "autonomia e a liberdade fazem parte da própria natureza do ato pedagógico. O significado de autonomia remete-nos para regras e orientações criadas pelos próprios sujeitos da ação educativa, sem imposições externas" (VEIGA, 1995, p. 4). Todavia, observa-se que mesmo tendo autonomia para definir as concepções que orientam as finalidades socioeducativas, as escolas não demonstram uma coerência nesse posicionamento. Desde 2007, deveriam seguir as orientações curriculares do currículo AMOP, mas as concepções de homem, de mundo, de conhecimento, de currículo, de educação e de escola apresentadas em sua maioria não condizem com o disposto no documento curricular.

No entanto, "para ser autônoma, a escola não pode depender dos órgãos centrais e intermediários que definem a política da qual ela não passa de executora" (VEIGA, 1995, p. 6). Nessa perspectiva, é necessário que a escola assuma suas responsabilidades. Para que isso aconteça é necessário fortalecer as relações 
entre as instituições normativas e a escola. Portanto é necessário encontrar o equilíbrio já que o Projeto Político-Pedagógico deve ser construído e vivenciado no processo educativo e não somente arquivado ou encaminhado para as autoridades educacionais. Outro ponto importante a ser levantado é que "faz-se necessário, também, o domínio das bases teórico-metodológicas indispensáveis à concretização das concepções assumidas coletivamente" (VEIGA, 1995, p. 2).

Como apresentado, a partir da implantação do Currículo Básico para as escolas municipais do Oeste do Paraná, tornou-se necessário planejar e organizar formação continuada enquanto política educacional no que se refere à formação de professores, para a discussão e sistematização da proposta curricular adotada nas escolas municipais da região. A importância das políticas de formação continuada dos trabalhadores da educação foi assegurada no Art. no 67, da LDB 9394/96. Além de que, na fase de construção e implantação do currículo, também se vivenciava um contexto de mudanças tecnológicas, respaldado pela ideologia da globalização e defendido pela política neoliberal.

As ideias neoliberais, segundo Shiroma (1999), seguem a lógica dos organismos internacionais, "articulando-se a partir de conceitos como competitividade, produtividade, eficiência, eficácia, eqüidade, competências, novas qualificações, entre outros, destacam a educação como elemento estratégico para a implementação dos processos de modernização almejados" (SHIROMA, 1999, p. 484). Sob esse aspecto as demandas impostas pelo mercado de trabalho, influenciam a reestruturação das políticas curriculares da atualidade.

Assim, Malanchen (2015) dispõe que os órgãos do governo brasileiro evidenciavam "a necessidade de adequação da atividade docente às novas exigências profissionais advindas das inovações tecnológicas e da consequente mudança do mundo do trabalho apregoado pelos princípios de flexibilidade e eficiência" (MALANCHEN, 2015, p.4). Nesse contexto de políticas públicas educacionais orientadas pelo Banco Mundial, Decker (2015, p.155) afirma que se pretendia "desenvolver a formação docente na perspectiva de treinamento", ou seja, modificar as práticas docentes dando ênfase ao pragmático em relação à formação teórica.

Nesse processo historicista, a publicação do documento curricular, em 2007, impôs aos munícipios a necessidade de realizar cursos de formação continuada para os professores, a fim de que tivessem conhecimento da teoria proposta no Currículo Básico: "Tal opção, na realidade, tinha como objetivo fazer com que o Currículo não se limitasse a um discurso de alguns, mas uma proposta que pudesse ser efetivada" (AMOP, 2014, p. 9). Pode-se dizer que o investimento em formação continuada deveria ir além de formações pontuais, sendo condição necessária para a consolidação do Currículo na região.

Assim, como parte do processo de construção da pesquisa, neste item, apresentamse os dados da formação continuada oferecida na rede municipal de Foz do Iguaçu no período de 2007 a 2017. A intenção aqui é de verificar se as formações continuadas buscavam consolidar, através da formação teórica, os pressupostos curriculares e qual teoria se materializava nas formações oferecidas aos professores por meio do NTM.

Os dados levantados no estudo demonstram uma preocupação com a melhoria da atuação docente desenvolvida por meio de formações orientadas para e pela prática, como dispõe Decker (2015):

\begin{tabular}{|c|}
\hline $\begin{array}{l}\text { eguindo as nova } \\
\text { endências, } \\
\text { reinamento é focad } \\
\text { a transmissão } d \\
\text { stratégias e técnica } \\
\text { ráticas, pelas quais } s\end{array}$ \\
\hline
\end{tabular}

Porém, não se observa uma preocupação com a oferta de cursos buscando a formação teórica do professor, e sim a formação com foco na prática, seguindo orientações da Organização de Cooperação e Desenvolvimento Econômico OCDE como disposto por Maués (2011):

Tanto a formação inicial, quanto a formação em 
serviço são importantes, devendo ambas possibilitar uma sólida formação teórica e prática da especialidade do professor (leitura, matemática, história), e os conhecimentos e as competências pedagógicas necessárias para transmitir seu saber de uma forma bem didática, motivar os alunos, avaliar o progresso da aprendizagem e adaptar o ensino às necessidades de cada aluno. Como se vê, não há uma preocupação maior com os conhecimentos relativos a disciplinas da área das Ciências Humanas, como Filosofia, Sociologia, Antropologia, Psicologia, que podem dar a sustentação necessária para que o professor situe os conhecimentos ministrados à realidade que o circunda de mais perto e no mundo como um todo (MAUÉS, 2011, p.78).

Diante do exposto podemos dizer que as formações ofertadas na rede primavam pela prática, buscando desenvolver as competências pedagógicas, necessárias para a transmissão do saber de forma a motivar e adaptar o ensino as necessidades do alunado, ao cotidiano, como proposto nas pedagogias da atualidade. Ao dar sequência à análise, percebe-se que, em 2017, com a mudança de gestão na rede municipal, houve uma pequena alteração no processo de formação continuada, por meio da parceira com a Universidade Estadual do Oeste do Paraná UNIOESTE e com a Universidade Federal de Integração Latino Americana -UNILA. Através dessas parcerias, nota-se o início de um processo de formação voltada ao desenvolvimento dos pressupostos presentes no Currículo, ou seja, "a formação do professor, importante promotor da formação da classe trabalhadora" (DECKER, 2015, p.155). Porém, ainda se observa uma oferta maior de formações voltadas ao desenvolvimento da prática no trabalho educativo com o intuito de desenvolver uma formação funcional do professor em detrimento de formações voltadas ao desenvolvimento teórico do mesmo.

\section{CONCLUSÕES}

Enfim, ao verificar os documentos direcionadores da educação pública municipal de Foz do Iguaçu, a intenção era encontrar dados que respondessem ao nosso problema de pesquisa, assim, buscou-se encontrar nesses documentos dados que apontassem qual teoria se apresentava na proposta educacional nas políticas curriculares desenvolvidas na rede municipal e se essa teoria se apresenta de forma objetiva nos projetos políticos-pedagógicos e na formação continuada ofertada aos professores da rede municipal. Sendo que, a hipótese inicial era que a teoria que direcionou as ações desenvolvidas, desde o ano de 2007, não foi não foi exclusivamente a da pedagogia históricocrítica.

Diante do exposto no Currículo AMOP (2014), verificou-se que o método apresentado na proposta curricular é o método materialista histórico e dialético e que a concepção de desenvolvimento humano se baseia na psicologia histórico-cultural, porém, não se menciona a pedagogia histórico-crítica enquanto teoria pedagógica, apesar de ser possível identificar a presença dos pressupostos dessa teoria no documento. Consequentemente revela a ausência de direção e a influência do multiculturalismo.

Quanto à organização dos Projetos político-pedagógicos, verificou-se que a orientação para a construção desse documento nas escolas municipais deveria ser uma elaboração conforme os pressupostos do Currículo AMOP, ou seja, deveria conter os elementos do materialismo histórico e dialético, da psicologia histórico-cultural e da pedagogia histórico-crítica. Porém, a maioria das escolas não conseguiu definir em seu marco conceitual de forma clara essa fundamentação, talvez pela necessidade de um domínio das bases teóricas do documento curricular ou porque a escola enquanto instituição social, inserida na sociedade capitalista, reflita no seu interior as determinações e contradições dessa sociedade.

Em relação à formação continuada dos professores municipais, observou-se que os poucos momentos de discussão da teoria curricular aconteceram devido à reformulação do currículo organizada pela AMOP como proposto no documento curricular. As formações ofertadas 
na rede municipal "incidiram em formação da subjetividade e na atuação docente, fomentando a individualização e a fragmentação política entre os professores" (DECKER, 2015, p.143), pois, em sua maioria, foram compostas de eventos pontuais e dificilmente garantiram 0 aprofundamento teórico-metodológico necessário à formação do professor.

As reflexões, com base nos estudiosos dessa temática, nos permitem afirmar que um currículo por si só não garante sua efetivação, sendo que as políticas curriculares desenvolvidas ainda apresentam muitas limitações para que esse documento seja realmente aplicado na rede pública municipal de educação. Dessa maneira é possível afirmar que as políticas desenvolvidas pelos gestores para efetivação dessa proposta na rede municipal de Foz do Iguaçu não definiram essa pedagogia como direcionadora de suas ações. Enfim, o presente estudo identificou a necessidade de aprofundar os conceitos teóricos da pedagógica histórico-crítica e ainda se pode destacar a necessidade de algumas intervenções a fim de garantir sua efetivação na rede municipal.

\section{REFERÊNCIAS}

AMOP. Associação dos Municípios do Oeste do Paraná. Currículo básico para a Escola Pública Municipal: Educação Infantil e Ensino Fundamental - anos iniciais Cascavel: AMOP, 2014.

ANDRÉ, T. C. Teorias da pesquisa em educação e ensino: esboço didático a partir do método de Marx. Revista Trama, Marechal Candido Rondon, v, 14, n. 33, p. 03-14, 2018.

ANTUNES. C.S. A escola do trabalho: formação humana em Marx. 2016. 184f. Tese (Doutorado em Educação na área de concentração de Filosofia e História da Educação) - Universidade Estadual de Campinas, SP, 2016.

BRASIL. Lei no 9.394, de 20 de dezembro de 1996. Estabelece as diretrizes e bases da educação nacional. Diário Oficial [da República Federativa do Brasil], Brasília, DF, v. 134, n. 248, 23 dez. 1996. Seção I, p. 27834-27841. Disponível em https://www.jusbrasil.com.br/topicos/11694640/ artigo-12-da-lei-n-9394-de-20-de-dezembro-de1996. Acesso em: 08 set. 2018.
BUENO, J. Z. Ética marxista e formação moral na escola. In: MARSIGLIA, A. N. C. G. (Org.). Pedagogia histórico-crítica: $\mathbf{3 0}$ anos. Campinas, SP: Autores Associados, 2011, p. 91-100.

DECKER, A. I. A formação docente no projeto político do Banco Mundial (2000-2014). 2015, 234f. Dissertação (mestrado) - Universidade Federal de Santa Catarina, Centro de Ciências da Educação. Programa de Pós-Graduação em Educação. Florianópolis, SC, 2015.

DELLA FONTE, S. S. Fundamentos teóricos da pedagogia histórico-crítica. In: MARSIGLIA, A. N. C. G. (Org.). Pedagogia histórico-crítica: 30 anos. Campinas, SP: Autores Associados, 2011, p. 2339.

DUARTE, N. A Importância da Concepção de Mundo para a Educação Escolar: Porque a Pedagogia Histórico-Crítica não endossa o silêncio de Wittgenstein. Germinal: Marxismo e Educação em Debate, Salvador, v. 7, n. 1, p. 8-25, jun.

2015.

https://doi.org/10.9771/gmed.v7i1.12808

DUARTE, N. Os conteúdos escolares e a ressurreição dos mortos: contribuição à teoria histórico-crítica do currículo. Campinas: Autores Associados, 2016.

EMER, I. O. Desenvolvimento histórico do Oeste do Paraná e a construção da escola. Rio de Janeiro: IESAE/FGV. Mímeo, 1991.

FRIGOTTO, G. O enfoque da dialética materialista histórica na pesquisa educacional. In: FAZENDA, I. (Org.). Metodologia da Pesquisa Educacional. 9 ed. São Paulo: Cortez, 2004. p. 71-90.

MALANCHEN, J. Políticas de formação de professores à distância no Brasil: uma análise crítica. Campinas: Autores Associados, 2015.

MALANCHEN, J. Cultura, conhecimento e currículo: contribuições da pedagogia históricocrítica. Campinas: Autores Associados, 2016.

MARTINS, L. M. Pedagogia histórico-crítica e Psicologia histórico-cultural. In: MARSIGLIA, A. N. C. G. (Org.). Pedagogia histórico-crítica: 30 anos. Campinas, SP: Autores Associados, 2011. p. 4357. 
MAUÉS, O.C. A política da OCDE para a educação e a formação docente. A nova regulação? Revista Educação, Porto Alegre, v. 34, n. 1, p. 75-85, jan./abr. 2011.

ORSO, P. J. Os desafios de uma educação revolucionária. In: ORSO, P. J.; MALANCHEN, J.; CASTANHA, A. P. (Orgs.). Pedagogia históricocrítica, educação e revolução: 100 anos da Revolução Russa. Campinas: Armazém do Ipê, 2017. p. 147-167.

ORSO, P. J.; MALANCHEN, J. Pedagogia históricocrítica e a defesa do saber objetivo como centro do currículo escolar. In: Seminário do HISTEDBR 30 Anos do HISTEDBR (1986-2016) Contribuições para a História e Historiografia da Educação Brasileira,10, 2016, Campinas. Anais... UNICAMP, 2016.

PARANÁ. Instrução Normativa no 003/2015 SUED/SEED. Disponível em http://www.educacao.pr.gov.br/arquivos/File/ins trucoes2015 sued seed/instrucao00315sued se ed.pdf. Acesso em: 01 de dezembro de 2018.

SAVIANI, N. Saber escolar, currículo e didática: problemas da unidade conteúdo/ método no processo pedagógico. 3. ed. Campinas: Autores Associados, 2000.

SAVIANI, D. Educação Socialista, Pedagogia Histórico-Crítica e os desafios da sociedade de classes. In: LOMBARDI, J. C.; SAVIANI, D. (Orgs). Marxismo e Educação - Debates Contemporâneos. Campinas: Autores Associados, 2008. p. 223-274.

SAVIANI, D. Escola e Democracia. 42. ed. Campinas: Autores Associados, 2012.

SAVIANI, D. Pedagogia histórico-crítica: primeiras aproximações. 11. ed. Campinas, SP. Autores Associados, 2013.

SAVIANI, D. O Lunar de Sepé: paixão, dilemas e perspectivas na educação. Campinas: Autores Associados, 2014.

SAVIANI, D. Educação escolar, currículo e sociedade: o problema da Base Nacional Comum Curricular. Movimento Revista de Educação. Rio de Janeiro, v. 3, n. 4, p. 54-84, 2016. Disponível em: http://www.revistamovimento.uff.br/index.php/r evistamovimento/article/view/296/301 Acesso em: 15 jul. 2018.

SEVERINO. J. A. O projeto político-pedagógico: a saída para a escola. Revista de Educação AEC, Brasilia, v. 27, n. 107, p. 85-91, 1998.

SHIROMA, E. O. O resgate da Escola Nova pelas reformas educacionais contemporâneas. Estudos, Brasília, v. 80, n. 196, p. 483-493, set./dez. 1999.

VEIGA, I. P. A. Projeto político-pedagógico da escola: uma construção possível. 29 ed. Campinas: Papirus, 1995. 